\title{
Electrochemical immunosensor for ethinylestradiol using diazonium salt grafting onto silver nanoparticles-silica-graphene oxide hybrids
}

\author{
Fernando H. Cincotto ${ }^{a}$, Gonzalo Martínez-García ${ }^{c}$, Paloma Yáñez-Sedeño ${ }^{\text {c,* }}$, \\ Thiago. C. Canevari ${ }^{b}$, S.A.S. Machado ${ }^{a}$, José M. Pingarrón ${ }^{c}$ \\ a Institute of Chemistry, State University of São Paulo, São Carlos, Brazil \\ ${ }^{\mathrm{b}}$ Engineering School, Mackenzie Presbiterian University, São Paulo, Brazil \\ ${ }^{\mathrm{c}}$ Department of Analytical Chemistry, Faculty of Chemistry, University Complutense of Madrid, Madrid, Spain
}

\section{A R T I C L E I N F O}

Article history:

Received 10 August 2015

Received in revised form

18 September 2015

Accepted 24 September 2015

Available online 1 October 2015

\section{Keywords:}

Ethinylestradiol

EE2

Electrochemical immunosensor

Silver nanoparticles

Graphene oxide

Urine

\begin{abstract}
A B S T R A C T
This work describes the preparation of an electrochemical immunosensor for ethinylestradiol (EE2) based on grafting of diazonium salt of 4-aminobenzoic acid onto a glassy carbon electrode modified with silver nanoparticles $/ \mathrm{SiO}_{2} /$ graphene oxide hybrid followed by covalent binding of anti-ethinylestradiol (anti-EE2) to activated carboxyl groups. A competitive immunoassay was developed for the determination of the hormone using peroxidase-labeled ethinylestradiol (HRP-EE2) and measurement of the amperometric response at $-200 \mathrm{mV}$ in the presence of hydroquinone (HQ) as redox mediator. The calibration curve for EE2 exhibited a linear range between 0.1 and $50 \mathrm{ng} / \mathrm{mL}\left(r^{2}=0.996\right)$, with a detection limit of $65 \mathrm{pg} / \mathrm{mL}$. Interference studies with other hormones related with EE2 revealed the practical specificity of the developed method for the analyte. A good reproducibility, with $\mathrm{RSD}=4.5 \%(n=10)$ was also observed. The operating stability of a single bioelectrode modified with anti-EE2 was maintained at least for 15 days when it was stored at $4{ }^{\circ} \mathrm{C}$ under humid conditions between measurements. The developed immunosensor was applied to the analysis of spiked urine with good results.
\end{abstract}

(c) 2015 Elsevier B.V. All rights reserved.

\section{Introduction}

Ethinylestradiol (EE2) is one of the most potent synthetic estrogenic hormones. It is an essential constituent of oral contraceptives widely prescribed in women [1,2]. Adverse effects of EE2 include accelerated coagulation and fibrinolysis. Furthermore, use of combined hormonal contraceptives has shown to be associated with increased risk of venous thrombosis depending on estrogen concentration $[3,4]$. EE2 is rapidly absorbed orally, yielding a peak in plasma between 1 and $2 \mathrm{~h}$ after taking [5]. A major challenge is the presence of residues of EE2 and its derivatives in the environment coming from excretions, where negative impact on the reproductive system in wildlife and human can be produced [6].

The relevance of EE2 determination both in biological and environmental samples has made available a large number of analytical methods. In addition to chromatography using GC or HPLC coupled to at least one mass spectrometer, various immunoassay methods have been developed. RIA and ELISA methods were reported early to determine EE2 in body fluids $[7,8]$. Currently, various ELISA kits are available for the analysis of biological samples or water. Table 1 summarizes the analytical characteristics of some

\footnotetext{
* Corresponding author.
}

of these configurations. A typical assay is based on competitive interaction between EE2 and biotinylated EE2 for the binding sites of a pre-coated specific antibody. Colorimetric detection using a peroxidase conjugate, $\mathrm{H}_{2} \mathrm{O}_{2}$ and TMB, allows the EE2 determination to be performed in a non-linear dynamic range extending up to thousands of $\mathrm{pg} / \mathrm{mL}$, and with an analysis time lasting about 2$2.5 \mathrm{~h}$ [6]. Other immunoassay formats using fluorimetric [9] or chemiluminiscence measurements [10] were also described. A competitive microfluidic immunoassay based on the immobilization of anti-EE2 on 3-aminopropyl functionalized magnetic beads and amperometric detection, was also reported [11]. Regarding immunosensors, a configuration was proposed using magnetic beads functionalized with a synthetic estrogen derivative. Competitive immunoassay with anti-EE2, alkaline phosphatase-labeled IgG, and 1-naphthyl phosphate, allowed the determination of the estrogen with a limit of detection of $10 \mathrm{pg} / \mathrm{mL}$ using square wave voltammetric detection [12].

Hybrid materials prepared from graphene and $\mathrm{SiO}_{2}$ constitute excellent substrates for the development of electrochemical sensors. The huge conductivity, high surface area, biocompatibility and robustness of graphene, coupled with the physical and chemical resistance of silica, its hydrophylicity, chemical inertness, and the high surface area/volume ratio, all contribute to increase the electroactive surface, thus enhancing sensitivity [13]. On the 


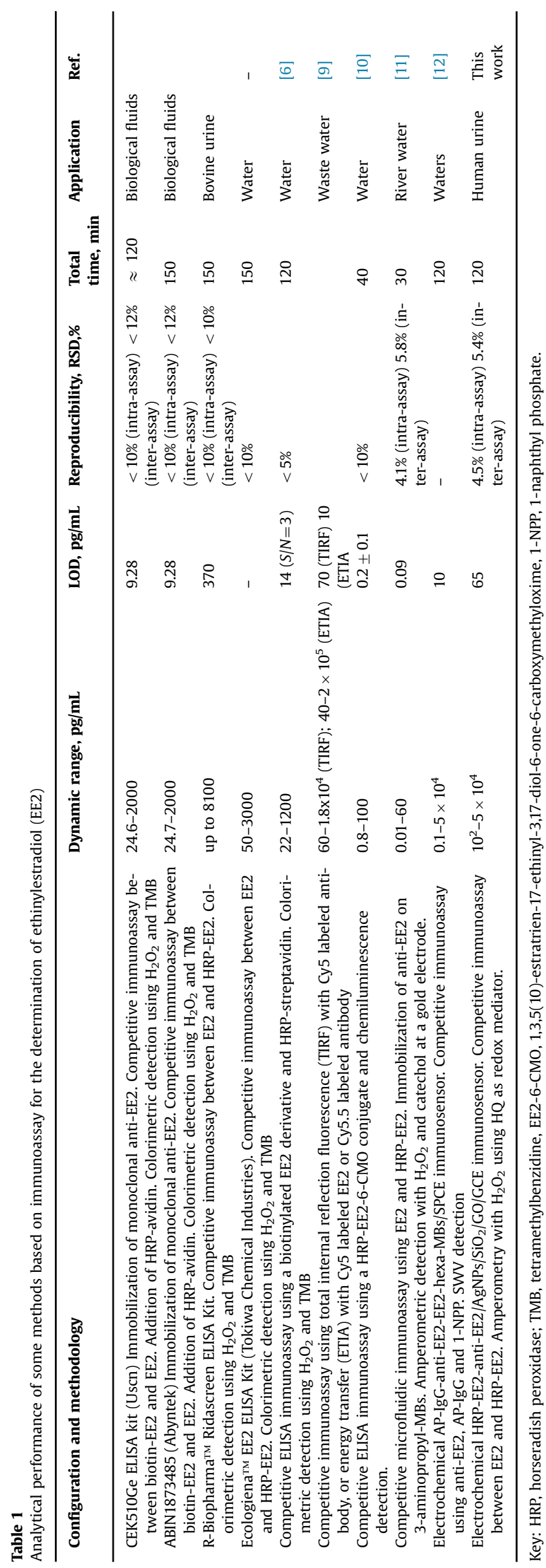

other hand, metallic nanoparticles are characterized by their electrocatalytic ability together with the capacity for adsorption of biomolecules, biocompatibility and high conductivity. In this context, it has been claimed that functionalization of graphene with $\mathrm{SiO}_{2}$ allows anchoring metal nanoparticles securely onto graphene support with a high dispersion thus enhancing the catalytic performance [14]. Despite their properties, only few examples of the use of metallic nanoparticles/silica/graphene hybrids can be found in the literature in connection to the preparation of electrochemical (bio)sensors. A hybrid material prepared with gold nanoparticles (AuNPs) immobilized onto mesoporous silica-coated reduced graphene oxide (rGO) was reported for cancer cell detection through hydrogen peroxide sensing [15]. Moreover, an interleukin-6 (IL-6) electrochemical immunosensor was prepared making use of AuNPs-graphene-silica sol-gel as immobilization biointerface and AuNP-poly-dopamine (PDA) @carbon nanotubes as the label of HRP-bound antibodies [16]. Recently, Cincotto et al. [17] reported the synthesis and characterization of $\mathrm{AgNPs} / \mathrm{SiO}_{2} / \mathrm{GO}$ hybrid and the preparation of a voltammetric sensor for the simultaneous determination of epinephrine and dopamine in urine. A good distribution of silver nanoparticles in the $\mathrm{SiO}_{2} / \mathrm{GO}$ material was found with a synergistic effect among the hybrid components producing electrocatalytic activity toward the electrochemical responses thus leading to a high sensitivity and selectivity.

The work described in this manuscript faces the double objective of addressing the lack of immunosensors for the determination of EE2, and explores for the first time the ability of $\mathrm{AgNPs} / \mathrm{SiO}_{2} / \mathrm{GO}$ hybrids for the preparation of electrochemical immunosensors. The designed strategy for capture antibodies immobilization involved 4-aminobenzoic acid (ABA) grafting onto $\mathrm{AgNPs} / \mathrm{SiO}_{2} / \mathrm{GO}$ glassy carbon (GCE) modified electrodes by electrochemical reduction of the corresponding diazonium salt. This strategy provided a suitable surface for covalent attachment of the capture antibody allowing the development of a competitive immunoassay for the determination of the hormone using peroxidase-labeled ethinylestradiol (HRP-EE2), and measuring the amperometric response at $-200 \mathrm{mV}$ upon addition of $\mathrm{H}_{2} \mathrm{O}_{2}$ in the presence of hydroquinone (HQ) as redox mediator.

\section{Experimental}

\subsection{Reagents and solutions}

Graphite (Aldrich), tetraethylorthosilicate (TEOS, Sigma-Aldrich, 98\%) and silver nitrate (Sigma-Aldrich, 99\%) were used for the synthesis of the hybrid material. 4-aminobenzoic acid (ABA, Across), 1-ethyl-3-[3-dimethylaminopropyl]carbodiimide hydrochloride (EDC, Sigma) and N-hydroxysulfo-succinimide (NHSS, Sigma), were also used. Ethinylestradiol (EE2, Aldrich), anti-ethinyl-estradiol (anti-EE2), and HRP-labeled ethinylestradiol (HRPEE2), both from Fitzgerald, were the reagents used for the immunosensor preparation. $0.1 \mathrm{M}$ phosphate buffer solutions of $\mathrm{pH}$ 7.2 (PBS) and pH 6.0 were prepared from $\mathrm{NaH}_{2} \mathrm{PO}_{4}$ and $\mathrm{Na}_{2} \mathrm{HPO}_{4}$ (Scharlau, 99\%). Blocker casein in PBS (Thermo), hydroquinone ( $\mathrm{HQ}$, Sigma), and $\mathrm{H}_{2} \mathrm{O}_{2}$ (Scharlau, 35\%) were also employed.

Cortisol, $\beta$-estradiol (E2), estriol (E3), progesterone (Prog) and testosterone (Test), all from Sigma, were tested as potential interfering compounds. Solutions of each compound at a $10^{-3}$ $\mu \mathrm{g} / \mathrm{mL}$ concentration in PBS were prepared. All other chemicals and solvents used were of analytical-reagent grade and distilled water was obtained from a Milli-Q purification system (Millipore, Bedford, NA, USA). 


\subsection{Apparatus}

Voltammetric measurements were carried out using a PGSTAT 101 potentiostat from Autolab controlled by Nova 1.6 electrochemical software (EcoChemie B.V.). A dual-channel ultrasensitive INBEA potentiostat (Inbea biosensores S.L. Spain) was used for amperometric measurements. A three electrodes (BAS VC-2 10$\mathrm{mL}$ ) glass electrochemical cell was used. Modified 3-mm diameter CHI 104 glassy carbon electrodes from $\mathrm{CH}$ Instruments were utilized as working electrodes. The reference electrode was an $\mathrm{Ag}$ / $\mathrm{AgCl} / \mathrm{KCl} 3 \mathrm{M}$ BAS MF 2063 and the auxiliary electrode was a BAS MW1032 Pt wire. All the electrochemical experiments were performed at room temperature. A P-Selecta ultrasonic bath, an Optic Ivymen System constant temperature incubator shaker (Comecta S.A.), and a P-Selecta Agimatic magnetic stirrer, all distributed by Scharlab, Madrid, Spain, were also used.

\subsection{Procedures}

\subsubsection{Preparation of $\mathrm{AgNPs} / \mathrm{SiO}_{2} / \mathrm{GO}$ Hybrid}

The method used was that reported in Ref. [17]. Briefly, $10 \mathrm{~g}$ of each graphite and $\mathrm{NaNO}_{3}$ were dispersed in $46 \mathrm{~mL}$ of concentrated sulfuric acid by continuous stirring in an ice bath. Then, $6.0 \mathrm{~g}$ of $\mathrm{KMnO}_{4}$ were slowly added under stirring, and the reaction mixture was kept on ice for $24 \mathrm{~h}$. Thereafter, $240 \mathrm{~mL}$ of water were added and temperature of the stirred solution was raised to $98{ }^{\circ} \mathrm{C}$ for $1 \mathrm{~h}$. After addition of $85 \mathrm{~mL}$ of $30 \%(\mathrm{v} / \mathrm{v}) \mathrm{H}_{2} \mathrm{O}$ the resulting product (GO) was filtered, washed three times with $5 \%(\mathrm{v} / \mathrm{v}) \mathrm{HCl}$, and dried at $50{ }^{\circ} \mathrm{C}$ for $48 \mathrm{~h}$.

The $\mathrm{SiO}_{2} / \mathrm{GO}$ hybrid was prepared by dispersing $4.5 \mu \mathrm{mol}$ of TEOS in $1 / 1(\mathrm{v} / \mathrm{v})$ ethanol under stirring for $10 \mathrm{~min}$. Then, $0.4 \mathrm{~mL}$ of water and $90 \mathrm{mg}$ of GO were added. The suspension was stirred for $10 \mathrm{~min}$ and $30 \mu \mathrm{L}$ of hydrofluoric acid (47\%) were added under sonication until gel formation. The obtained gel was stored at room temperature for up to seven days and then grounded. The resulting powder was washed with ethanol in a Soxhlet for $2 \mathrm{~h}$, and heated at $50{ }^{\circ} \mathrm{C}$ to evaporate residual solvent.

$\mathrm{AgNPs} / \mathrm{SiO}_{2} / \mathrm{GO}$ was prepared by adding $0.5 \mathrm{~g}$ of $\mathrm{SiO}_{2} / \mathrm{GO}$ to $15 \mathrm{~mL}$ of an $8 \times 10^{-3} \mathrm{M} \mathrm{AgNO}_{3}$ solution in dimethylformamide (DMF). The mixture was sonicated for $1 \mathrm{~h}$ at $25^{\circ} \mathrm{C}$ in the dark and the solid was recovered by centrifugation, washed with DMF, and treated at $110{ }^{\circ} \mathrm{C}$ for $4 \mathrm{~h}$ in a furnace.

\subsubsection{Preparation of the EE2 immunosensor}

The GCE surface was polished with $0.3 \mu \mathrm{m}$ alumina slurries, rinsed thoroughly with deionized water, sonicated for $5 \mathrm{~min}$ in ethanol and $5 \mathrm{~min}$ in water, and dried in air. Then, the polished electrode was electrochemically cleaned by repetitive cyclic voltammetry in $0.1 \mathrm{M}$ sulfuric acid over the $0-1 \mathrm{~V}$ vs. $\mathrm{Ag} / \mathrm{AgCl}$ potential range. $\mathrm{AgNPs} / \mathrm{SiO}_{2} / \mathrm{GO} / \mathrm{GCEs}$ were prepared by suspending $0.5 \mathrm{mg} \mathrm{AgNPs} / \mathrm{SiO}_{2} / \mathrm{GO}$ in $1 \mathrm{~mL} \mathrm{DMF}$ and sonicating for $10 \mathrm{~min}$. Then, $10 \mu \mathrm{L}$ of the resulting suspension were dropped onto the GCE surface and the modified electrode allowed to dry overnight.

Grafting of 4-aminobenzoic acid (ABA) diazonium salt was performed as follows (see Fig. 1). Firstly, $20 \mathrm{mg}$ of ABA were dissolved in $2 \mathrm{~mL}$ of $1 \mathrm{M} \mathrm{HCl}$ and cooled with ice. Then, the diazonium salt was prepared by adding $2 \mathrm{mM} \mathrm{NaNO}_{2}$ aqueous solution dropwise to this solution ( $38 \mu \mathrm{L}$ for each $200 \mu \mathrm{L}$ ) with constant stirring. Next, $40 \mu \mathrm{L}$ from the resulting solution were placed onto the modified electrode and ten successive voltammetric cycles between 0.0 and $-1.0 \mathrm{~V}$ at $\nu=200 \mathrm{mV} / \mathrm{s}$ were carried out. Thereafter, the modified electrodes were washed thoroughly with water and methanol and dried at room temperature. In a second step, $10 \mu \mathrm{L}$ of an EDC/NHSS ( $0.1 \mathrm{M}$ each) aqueous solution prepared in $0.1 \mathrm{M}$ phosphate buffer of $\mathrm{pH} 6.0$ were placed onto the modified electrode and left to react for $1 \mathrm{~h}$. After rinsing with water and methanol, and drying, $10 \mu \mathrm{L}$ of a $20 \mu \mathrm{g} / \mathrm{mL}$ anti-EE2 solution were dropped onto the electrode and incubated at $37^{\circ} \mathrm{C}$ for $45 \mathrm{~min}$. Then, $20 \mu \mathrm{L}$ of a $1 \%$ casein blocking solution were deposited onto the anti-EE2-Phe-AgNPs/SiO $/ \mathrm{GO} / \mathrm{GCE}$, and left to incubate for $1 \mathrm{~h}$ at $37^{\circ} \mathrm{C}$. In order to perform the competitive assay, $10 \mu \mathrm{L}$ of a mixture of the appropriated standard EE2 solution (or the sample) and 1/100 diluted HRP-EE2 were placed onto the electrode surface and incubated for $1 \mathrm{~h}$ at $37^{\circ} \mathrm{C}$. After each modification step, the modified electrode was washed with $0.1 \mathrm{M}$ PBS of pH 7.2. EE2 determination was accomplished in the same buffer solution by amperometric detection at $-0.20 \mathrm{~V}$ in the presence of $45 \mu \mathrm{L}$ of $1 \mathrm{mM}$ HQ after addition of $5 \mu \mathrm{L}$ of $50 \mathrm{mM} \mathrm{H}_{2} \mathrm{O}_{2}$.

\subsubsection{Determination of EE2 in urine}

Urine samples were collected from a healthy adult female volunteer. Samples were aliquoted and stored at $-20^{\circ} \mathrm{C}$, and

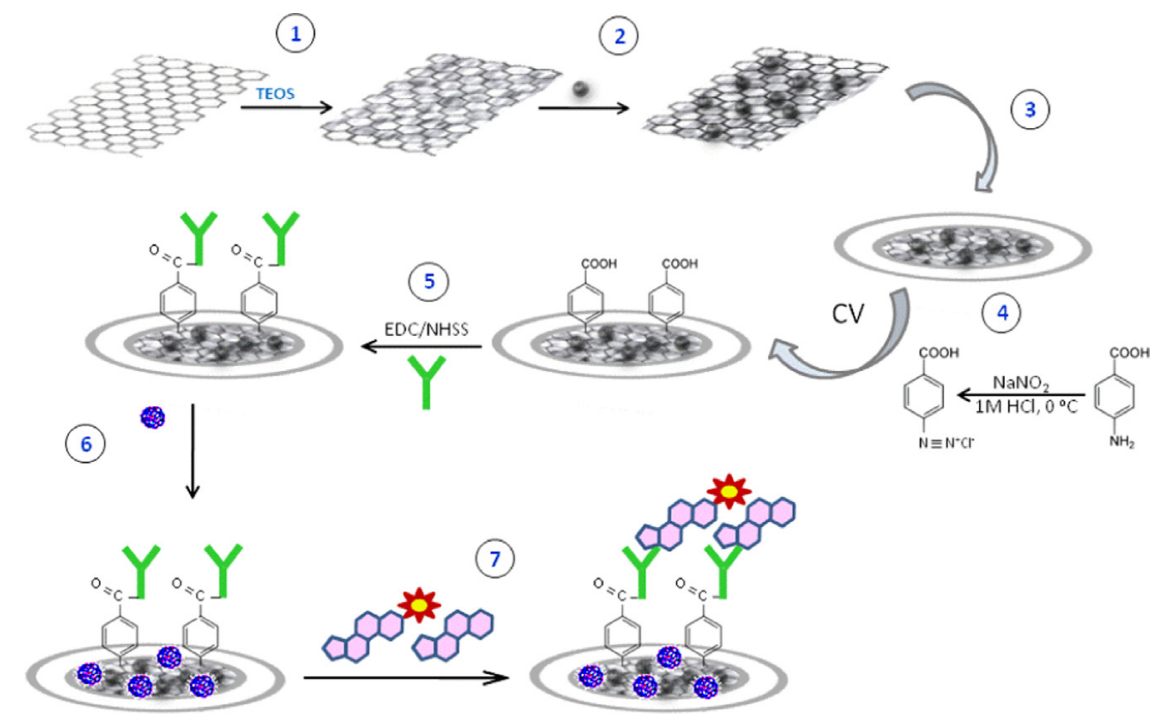

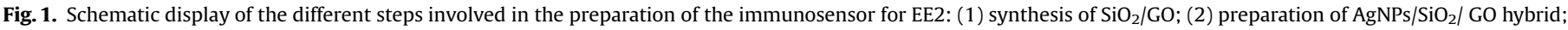

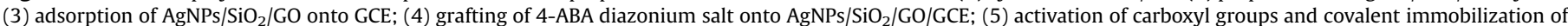
anti-EE2; (6) blocking with casein; (7) competitive assay between EE2 and HRP-EE2. 
analyzed directly upon dilution with buffer. It would be mentioned that all ethical and human rights guidelines in the sampling procedure were obeyed. The determination of EE2 was made by applying the experimental procedure described above to samples spiked with the hormone at $0.1 ; 0.5 ; 1.0$ and $10 \mathrm{ng} / \mathrm{mL}$ concentration levels.

\section{Results and discussion}

As it was commented in the Introduction section, this work explores for the first time the ability of $\mathrm{AgNPs} / \mathrm{SiO}_{2} / \mathrm{GO}$ hybrids for the preparation of electrochemical immunosensors, which can be justified by the synergistic effect found by Cincotto et al. among the hybrid components giving rise to enhanced electrocatalysis [17]. AgNPs/ $/ \mathrm{SiO}_{2} / \mathrm{GO}$ was prepared by mixing $\mathrm{SiO}_{2} / \mathrm{GO}$ gel with silver ions dissolved in DMF and sonicated for $1 \mathrm{~h}$ in the dark. This method led to the production of DMF radicals which were responsible for the formation of silver nanoparticles [18]. Characterization of this material by electron microscopy and X-ray techniques revealed the presence of graphene sheets incorporated in the silica matrix together with homogeneously distributed silver nanoparticles with a diameter around $20 \mathrm{~nm}$ [17]. Then, $\mathrm{AgNPs} / \mathrm{SiO}_{2} / \mathrm{GO} / \mathrm{GCEs}$ were prepared by dropping $10 \mu \mathrm{L}$ of AgNPs/SiO $/$ /GO hybrid suspènded in DMF on the GCE surface and allowing to dry overnight.

Fig. 1 illustrates the steps involved in the preparation of the developed immunosensor. As it was also described in Section 2.3.2, diazotized ABA was obtained by reaction with sodium nitrite in hydrochloride acid and the resulting 4-carboxybenzenediazonium ion solution was dropped onto the modified electrode surface. Cyclic voltammetric scans between 0.0 and $-1.0 \mathrm{~V}$ at $\nu=200 \mathrm{mV} / \mathrm{s}$ completed the grafting process. Thereafter, surface-confined carboxyl groups were activated with EDC/NHSS and anti-EE2 antibodies were covalently attached to the electrode through the formation of amide bonds. After a blocking step with casein, a competitive assay between EE2 and HRP-EE2 for the binding sites of the immobilized antibodies was accomplished. Hydrogen peroxide was used as the HRP substrate to detect the immunosensing event in the presence of hydroquinone, by measuring the amperometric response at $-200 \mathrm{mV}$ vs $\mathrm{Ag} / \mathrm{AgCl}$.

\subsection{Electrochemical characterization}

As commented above, the affinity reaction was electrochemically monitored using $\mathrm{H}_{2} \mathrm{O}_{2}$ as HRP substrate and a redox mediator. This was selected by checking the cyclic voltammetric responses recorded at the $\mathrm{AgNPs} / \mathrm{SiO}_{2} \mathrm{GO} / \mathrm{GCE}$ from $1 \mathrm{mM}$

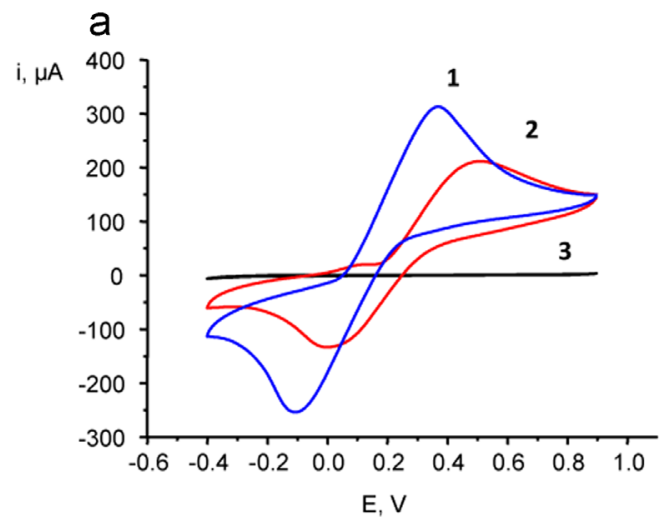

solutions of hydroquinone (HQ) or catechol in $0.1 \mathrm{M}$ PBS as they are commonly employed for this purpose. Although Fig. 2a shows that both compounds exhibited a quasi-reversible behavior at the modified electrode, the peak current values were considerably larger for $\mathrm{HQ}$ which was the selected for further work. Moreover, CVs for $1 \mathrm{mM}$ HQ solutions were recorded at GO/GCE, $\mathrm{SiO}_{2} / \mathrm{GO} / \mathrm{GCE}$ and $\mathrm{AgNPs} / \mathrm{SiO}_{2} / \mathrm{GO} / \mathrm{GCE}$ for comparison purposes. As it can be observed, the peak potential values obtained at the electrodes prepared without AgNPs were similar, with peak-topeak separation $(\Delta E)$ of ca. $600 \mathrm{mV}$ in both cases. However, a significant decrease of $136 \mathrm{mV}$ in the $\Delta E$ value was produced at the $\mathrm{AgNPs} / \mathrm{SiO}_{2} / \mathrm{GO} / \mathrm{GCE}$ and the peak current values were also larger (27\% and $15 \%$ for the anodic and cathodic peaks, respectively). These observations are in agreement with those previously reported for the electrochemical behavior of dopamine and epinephrine [17] and were attributed to the presence of AgNPs onto $\mathrm{SiO}_{2} / \mathrm{GO} / \mathrm{GCE}$ enhancing the electrocatalytic ability of the hybrid nanomaterial towards the quinone/hydroquinone electrochemical process.

Furthermore, the different modified electrodes were characterized by electrochemical impedance spectroscopy using $5 \mathrm{mM}$ $\mathrm{Fe}(\mathrm{CN})_{6}{ }^{3-14-} 0.1 \mathrm{M} \mathrm{KCl}$ as electrochemical probe. Fig. 3 shows the Nyquist plots recorded at GO/GCE (curve 1), $\mathrm{SiO}_{2} / \mathrm{GO} / \mathrm{GCE}$ (curve 2) and $\mathrm{AgNPs} / \mathrm{SiO}_{2} / \mathrm{GO} / \mathrm{GCE}$ (curve 3 ). As it can be seen, the charge transfer resistance at the GO/GCE $\left(R_{\mathrm{CT}}=1362 \Omega\right)$ is significantly higher than that at $\mathrm{SiO}_{2} / \mathrm{GO} / \mathrm{GCE}\left(R_{\mathrm{CT}}=331 \Omega\right)$, and decreased slightly after further modification with $\operatorname{AgNPs}\left(R_{\mathrm{CT}}=233 \Omega\right)$. These results can be explained taking into account the presence of graphene sheets incorporated into the porous of the silica matrix, thus providing a good conductivity for the $\mathrm{SiO}_{2} / \mathrm{GO}$ modified electrode. Furthermore, the $R_{\mathrm{CT}}$ value increased dramatically upon immobilization of anti-EE2 (curve 4), with $R_{\mathrm{CT}}=23342 \Omega$, because of the partially insulating barrier on the electrode surface due to the proteins immobilization.

\subsection{Capture antibodies immobilization}

Covalent binding of anti-EE2 can be achieved by carbodiimide chemistry with the activated carboxylic moieties present on the grafted electrode surface thus assuring stable immobilization [19]. The advantage of using the $\mathrm{AgNPs} / \mathrm{SiO}_{2} / \mathrm{GO}$ hybrid surface compared to bare GCE or intermediate assemblies is demonstrated by comparing the amperometric measurements recorded at immunosensors prepared by grafting of 4-ABA diazonium salt and covalent immobilization of anti-EE2 antibody onto the $\mathrm{AgNPs} / \mathrm{SiO}_{2} / \mathrm{GO} / \mathrm{GCE}$ and onto $\mathrm{SiO}_{2} / \mathrm{GO} / \mathrm{GCE}, \mathrm{GO} / \mathrm{GCE}$ and bare GCE (Fig. 4A). As it can be seen, the AgNPs/SiO $/$ GO/GCE immunosensor provided remarkably larger specific responses (corresponding to

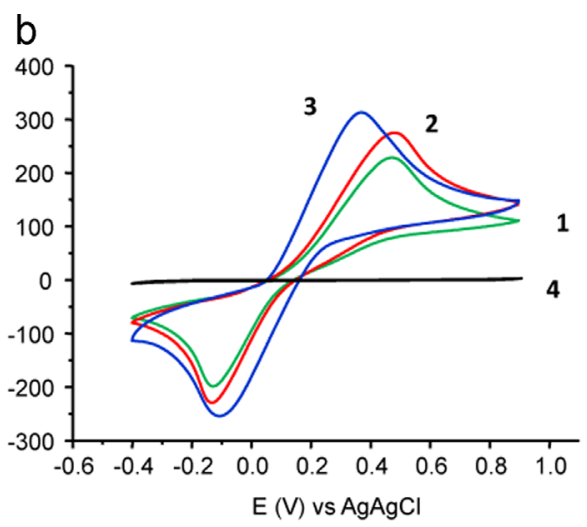

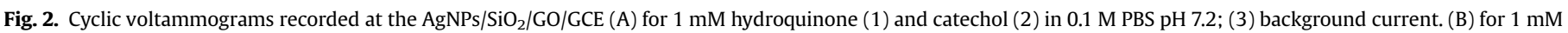
hydroquinone at (1) GO/GCE, (2) $\mathrm{SiO}_{2} / \mathrm{GO} / \mathrm{GCE}$ and (3) AgNPs/SiO $/$ /GO/GCE; (4) background current; $\nu=50 \mathrm{mV} / \mathrm{s}$. 

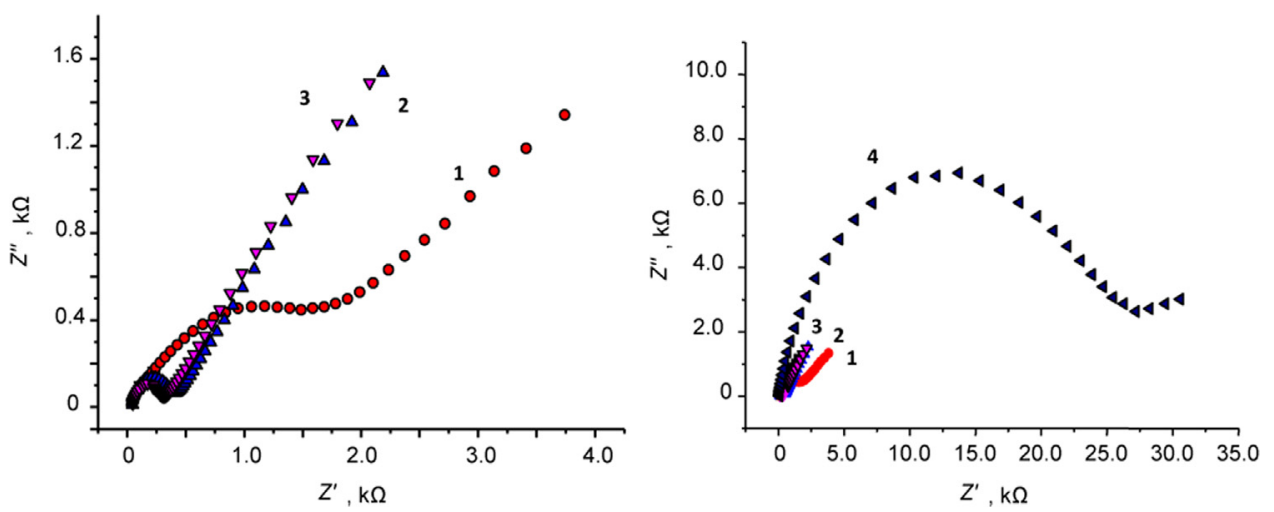

Fig. 3. Nyquist plots recorded at GO/GCE (1); $\mathrm{SiO}_{2} / \mathrm{GO} / \mathrm{GCE}(2) ; \mathrm{AgNPs} / \mathrm{SiO}_{2} / \mathrm{GO} / \mathrm{GCE}(3)$ and anti-EE2-Phe-AgNPs/SiO $/ \mathrm{GO} / \mathrm{GCE}(4) .5 \mathrm{mM} \mathrm{Fe}(\mathrm{CN})_{6}{ }^{3-} / 4-0.1 \mathrm{M} \mathrm{KCl}$

HRP-EE2 interaction at anti-EE2-Phe-AgNPs/ $\mathrm{SiO}_{2} / \mathrm{GO} / \mathrm{GCE}$ ) as a consequence of both the efficient immobilization of anti-EE2 and the improved electrochemical behavior found with the hybrid nanomaterial. Moreover, competitive signals (dark grey bars) were similar with the three nanostructured immunosensors thus indicating that a good competition between HRP-EE2 and EE2 for the binding sites of the immobilized antibodies occurred regardless the electrode composition. These responses were of small magnitude as corresponds to the relatively high EE2 concentration used. Regarding unspecific signals (black bars), i.e. those measured in the absence of capture antibody, low and similar values were observed at all the nanostructured electrodes while it was much larger at the bare GCE probably due to the adsorption of HRP-EE2 conjugate which also would explain the large competitive signal measured with the unmodified electrode.

Moreover, the benefits of the selected immobilization approach on the immunoassay performance were verified by comparing it with the results obtained by simple adsorption of anti-EE2 on the hybrid-modified electrode surface (Fig. 4B). As it is clearly observed, the immunosensor prepared by simple adsorption of the antibody onto $\mathrm{AgNPs} / \mathrm{SiO}_{2} / \mathrm{GO} / \mathrm{GCE}$ showed a much lower specific current than that measured with the immunosensor constructed by covalent anti-EE2 immobilization and, furthermore, it was similar to that corresponding to unspecific interactions. This different behavior should be attributed to the differences in antibody immobilization efficiency which may be also related to the different surface property due to the absence of the aryldiazonium layer [22]. However, it is interesting to note that even with this inefficient immobilization strategy, the competition still works although in a limited extension (dark grey column in Fig. 4B) which proved the suitable selection of immunoreagents.
3.3. Optimization of the experimental variables involved in the immunosensor preparation

The experimental conditions used to carry out grafting, i.e. diazotation and activation of carboxyl groups, were the same than those optimized by our group in the preparation of an electrochemical immunosensor for adrenocorticotropin [19]. Moreover, other variables affecting the performance of the developed immunosensor were optimized. These studies involved the evaluation of (i) the loading of antibody at $\mathrm{AgNPs} / \mathrm{SiO}_{2} / \mathrm{GO} / \mathrm{GCE}$ and the time for incubation; (ii) the blocking step; (iii) the HRP-EE2 loading onto the anti-EE2/AgNPs/SiO $/$ /GO/GCE and the time for incubation. Details on these optimization studies are provided in Supplementary material and in Fig S1-S3. A summary of the results is made in Table 2.

\subsection{Analytical characteristics for EE2 determination}

Fig. 5 shows the dependence of the biosensor amperometric response with EE2 concentration over the $5 \times 10^{-4}-5 \times 10^{3} \mathrm{ng} / \mathrm{mL}$ under the optimized experimental conditions. Error bars were calculated for measurements carried out with three different modified electrodes. As expected, a sigmoidal shape typical of a competitive enzyme immunoassay, in which binding of the antigen-enzyme conjugate (HRP-EE2) is inhibited by the addition of free antigen (EE2), and the concentration is inversely proportional to the free antigen added, was obtained [20]. The current vs. EE2 concentration was fitted by non-linear regression with the adjusted four parameters equation $\left(r^{2}=0.994\right)$ :

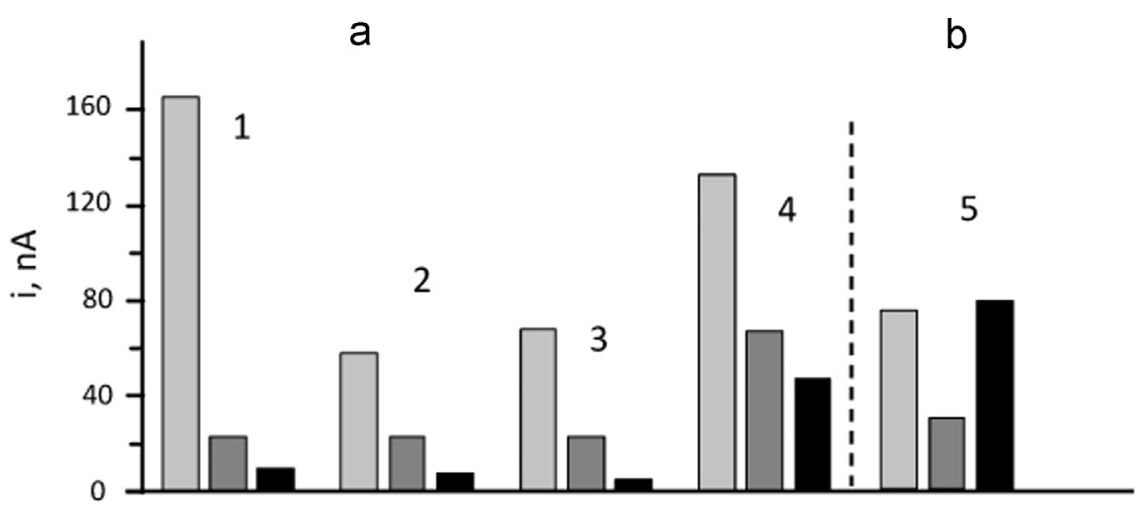

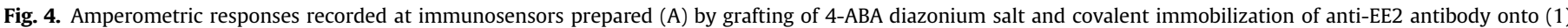

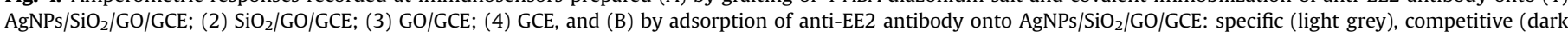

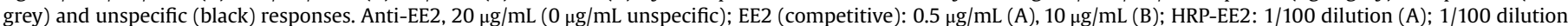
(B) (specific and unspecific), 1/50 dilution (competitive). See text for other conditions. 
Table 2

Optimization of the performance conditions of the HRP-EE2-anti-EE2/AgNPs/ $\mathrm{SiO}_{2} /$ GO/GCE immunosensor.

\begin{tabular}{lll}
\hline Variable & Tested range & Selected value \\
\hline Anti-EE2, $\mu \mathrm{g} / \mathrm{mL}$ & $0-50$ & 20 \\
Incubation time for anti-EE2, min & $0-120$ & 45 \\
Blocking agent type & Ethanolamine, casein, BSA & casein \\
Incubation time for blocking, min & $30-75$ & 60 \\
HRP-EE2, dilution & $1 / 200-1 / 50$ & $1 / 100$ \\
Incubation time for HRP-anti- & $30-75$ & 60 \\
$\quad$ APN, min & & \\
\hline
\end{tabular}

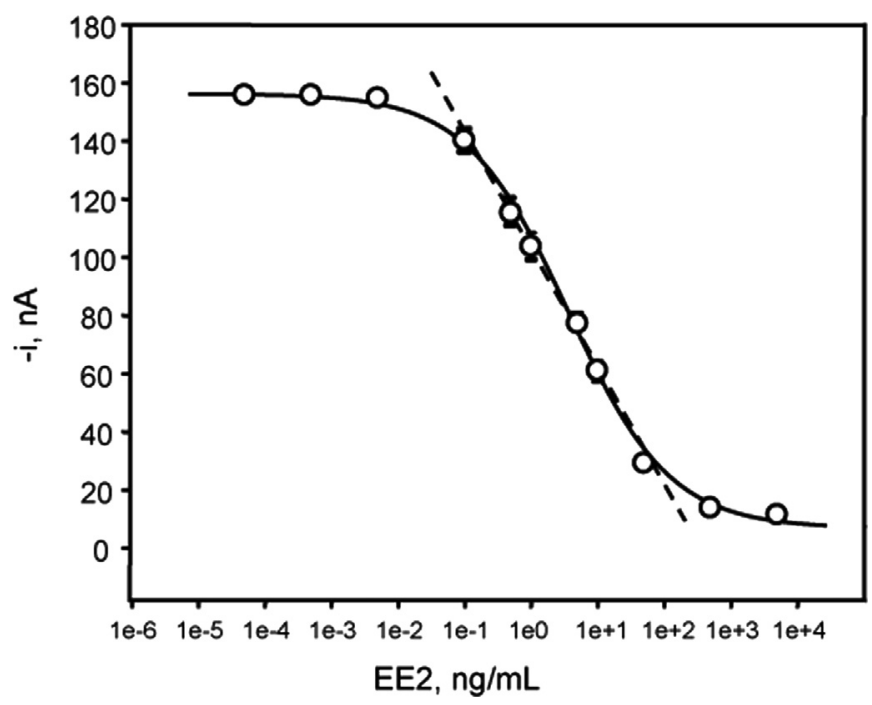

Fig. 5. Calibration plot for EE2 at the anti-EE2-Phe-AgNPs/SiO $/$ GO/GCE immunosensor. See text and Table 2 for the experimental conditions.

$y=i_{\min }+\frac{i_{\max }-i_{\min }}{1+\left(\frac{x}{E 50}\right)^{-h}}$

where $i_{\max }=155.6 \mathrm{nA}$ and $i_{\min }=6.1 \mathrm{nA}$ were the maximum and minimum current values of the calibration curve. The $\mathrm{EC}_{50}$ value, corresponding to the EE2 concentration for a fifty per cent inhibition, was $3.3 \mathrm{ng} / \mathrm{mL}$, while the Hill slope, $h$, which determines the curvature of the calibration graph and gives an idea of the assay sensitivity (with optimum values close to unity [21]) was -0.57 . Logit transformation of the sigmoidal curve by plotting Ln $\frac{p}{1-p}$ VS Ln $x$, with $p=\left(y-i_{\min }\right) /\left(i_{\max }-i_{\min }\right)$ provided a linear graph that deviated from linearity for EE2 concentration lower than $0.05 \mathrm{ng} / \mathrm{mL}$. The slope of such line was -0.59 , which appreciably coincides with the $h$ value mentioned above.

Least square fitting of the curve provided a linear current vs. log [EE2] plot $\left(r^{2}=0.994\right)$ extending between 0.1 and $50 \mathrm{ng} / \mathrm{mL}$ with a slope value of $41 \pm 1 \mathrm{nA}$, expressed as the current value per decade of EE2 concentration. The limit of detection was calculated as the lowest EE2 concentration that could be differentiated from zero. It was determined by subtracting two times the standard deviations ( $2 \mathrm{~s}$, with $s= \pm 4.7 \mathrm{nA}$ ) from the mean current of solutions containing no EE2. The calculated value was $0.065 \mathrm{ng} / \mathrm{mL}$ EE2 which is in agreement with the LOD value, $0.063 \mathrm{ng} / \mathrm{mL}$, calculated from the equation [21]:

$L O D=E C_{50}\left(\frac{i_{\max }-i_{\min }}{i_{\max }-i_{\min }-3 s}-1\right)-\frac{1}{h}$

The reproducibility of the measurements carried out with the immunosensor was also evaluated. Amperometric measurements for $0.1 \mathrm{ng} / \mathrm{mL}$ EE2 were made with immunosensors prepared on the same day or on five different days. The RSD values obtained were $4.5 \%(n=10)$ or $5.4 \%(n=10)$, respectively.

The achieved analytical characteristics of the immunosensor are suitable for the determination of EE2 in biological samples where concentrations in the range of tenths of $\mathrm{ng} / \mathrm{mL}$ are found [6]. The linear range of the calibration plot is much wider and the precision much higher than that reported with the ELISA kits. However, the detection limit obtained with the immunosensor is higher than the so-called minimum concentration detectable with the colorimetric assay $(9.28 \mathrm{pg} / \mathrm{mL})$ as well as the value obtained using the microfluidic immunoassay $(0.09 \mathrm{pg} / \mathrm{mL})$ [11]. Nevertheless, this comparison is not entirely correct since different criteria were used to calculate the mentioned values.

The storage stability at $4{ }^{\circ} \mathrm{C}$ of anti-EE2/AgNPs/SiO $/ 2 / G O / G C E$ conjugates was evaluated by measuring the amperometric response of immunosensors prepared after adding the blocking agent and the HRP-EE2 conjugate. The results obtained (not shown) revealed that the initial response of the immunosensor was maintained within the limits of control set at \pm 3 times the standard deviation of the measurements $(n=10)$ carried out on the first day, during at least 15 days after the immunosensor preparation, thus showing a good storage stability.

\subsection{Interferences study}

Various steroid hormones structurally related with ethinylestradiol such as cortisol, $\beta$-estradiol (E2), estriol (E3), progesterone and testosterone (see Fig S5 for the structures), were tested as potential interfering compounds. The effect of the presence of each compound was evaluated from the currents measured, under the optimal experimental conditions, using HRP-EE2-anti-EE2/AgNPs/SiO $/$ /GO/GCE conjugates for $1 \mathrm{ng} / \mathrm{mL}$ EE2 and interfering compound. Fig. 6 shows as only E2 and testosterone gave rise to relative current percentages very slightly above the limit corresponding to the $\pm 2 \mathrm{~s}$ range. This was also observed using other methodologies. For example, E2 showed higher cross-reactivity than that from other estrogenic hormones in the ELISA methods described by Schneider's group using spectrophotometric or chemiluminiscent detection [7,13]. Both compounds are structurally similar, being E2 the product of testosterone aromatization reaction, with the hydroxy group at the C-17 position and no other functional group incorporated into such a ring. Therefore, it can be concluded that the selected antibody is able to discriminate on the basis of these differences.

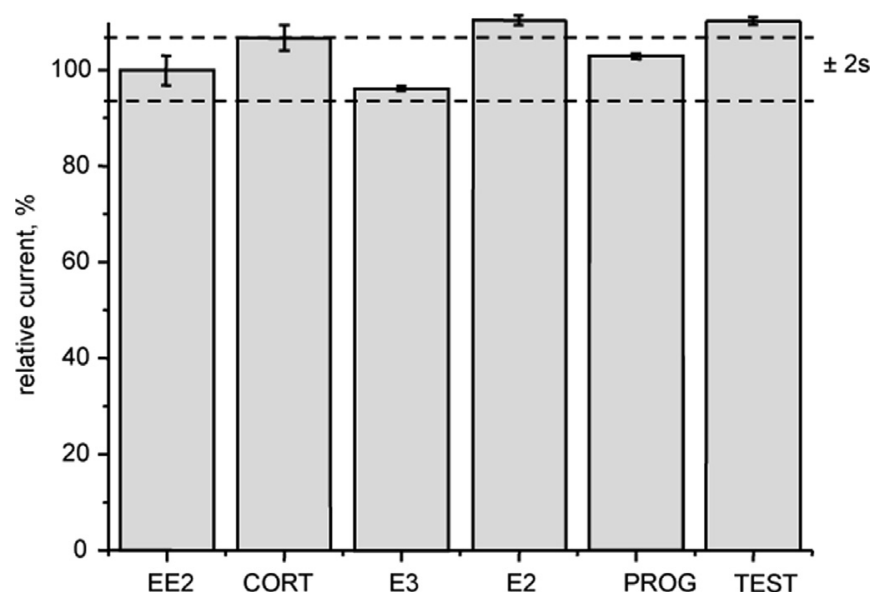

Fig. 6. Effect of the presence of cortisol, E3, E2, progesterone and testosterone on the amperometric responses obtained for $0 \mathrm{ng} / \mathrm{mL}$ EE2 with the anti-EE2-Phe-AgNPs/SiO $/$ /GO/GCE immunosensor. 
Table 3

Determination of EE2 in spiked urine with the HRP-EE2-anti-EE2/AgNPs/SiO $/ \mathrm{GO} /$ GCE immunosensor.

\begin{tabular}{llllc}
\hline Sample & $\begin{array}{l}\text { EE2 added, } \\
\mathbf{n g} / \mathbf{m L}\end{array}$ & EE2 found, $\mathbf{n g} / \mathbf{m L}$ & $\begin{array}{l}\text { EE2, mean value, } \\
\mathbf{n g} / \mathbf{m L}^{1}\end{array}$ & Recovery, \% \\
\hline 1 & 0.1 & $\begin{array}{l}0.097 ; 0.100 ; \\
0.095 ; 0.098 ; 0.098\end{array}$ & $0.098 \pm 0.002$ & $98 \pm 2$ \\
& & $\begin{array}{l}0.50 ; 0.51 ; \\
0.51 ; 0.50 ; 0.50\end{array}$ & $0.50 \pm 0.01$ & $100 \pm 1$ \\
3 & 0.5 & $\begin{array}{l}0.97 ; 1.0 ; 0.95: 0.98 ; \\
0.98\end{array}$ & $0.98 \pm 0.02$ & $98 \pm 2$ \\
4 & 1.0 & $\begin{array}{l}4.8 ; 4.7 ; 5.0 ; 4.8 ; \\
4.9\end{array}$ & $4.8 \pm 0.1$ & $96 \pm 1$ \\
& 5.0 & & & \\
\hline
\end{tabular}

a mean value $\pm \mathrm{ts} / \sqrt{ } n$.

\subsection{Determination of EE2 in spiked urine}

The applicability of the HRP-EE2-anti-EE2/AgNPs/SiO $/$ / GO/GCE immunosensor for the determination of EE2 in biological samples was demonstrated by analyzing urine which was spiked with the hormone at four different concentration levels: 0.1, 0.5, 1.0 and $10 \mathrm{ng} / \mathrm{mL}$. Previously, blanks of unspiked diluted urine were tested and no detectable content of the hormone was found. Then, as it was described in the Experimental section, the spiked samples were analyzed without any treatment step except dilution. In order to evaluate the existence of potential matrix effect, a calibration plot for EE2 in urine was constructed by appropriate dilution. Figure S5 displays the overlapped calibration plots constructed with standard EE2 solutions and from the diluted urine samples. The slope value calculated for the linear portion of this latter calibration plot was $38 \pm 2 \mathrm{nA}$ per decade of concentration. A statistical comparison using the Student $t$-test with the slope value of the calibration graph prepared with EE2 standards, $41 \pm 1 \mathrm{nA}$ per decade of concentration, showed that $t_{\exp }, 1.34$, was lower than the tabulated value, 2.306, for $n=8$, at a 0.05 significance level, indicating that no no significant differences existed between both slope values. Accordingly, significant matrix effect could be discarded and the determination of EE2 in human urine could be carried out simply by interpolation of the amperometric measurements from the sample solutions into the calibration plot constructed with standards. Table 3 summarizes the results obtained. As it can be observed, satisfactory recoveries, ranging between $96 \pm 1 \%$ and $100 \pm 1 \%$, were obtained for five replicates and for all the tested concentration levels.

\section{Conclusions}

An electrochemical immunosensor has been developed for the amperometric determination of the estrogenic hormone ethinylestradiol. The biosensor design explores for the first time the ability of prepared $\mathrm{AgNPs} / \mathrm{SiO}_{2} / \mathrm{GO}$ hybrids as a convenient scaffold for such purpose. Capture antibodies were covalently immobilized on activated 4-aminobenzoic acid grafted onto $\mathrm{AgNPs} / \mathrm{SiO}_{2} / \mathrm{GO}$ glassy carbon modified electrodes by electrochemical reduction of the corresponding diazonium salt. This immunoelectrode design together with the competitive immunoassay developed making use of peroxidase-labeled ethinylestradiol allowed the determination of the hormone over the $0.1-50 \mathrm{ng} / \mathrm{mL}$ linear concentration range and with a detection limit of $0.065 \mathrm{ng} / \mathrm{mL}$. These characteristics along with the high precision and selectivity exhibited by the immunosensor makes it highly appropriate for the determination of the estrogenic hormone in biological samples. This was demonstrated by analyzing human urine samples spiked with the analyte at four different concentration levels ranging from 0.1 to $10 \mathrm{ng} / \mathrm{mL}$

\section{Acknowledgments}

Financial support of Spanish Ministerio de Economía y Competitividad, Research ProjectCTQ2012-35041, and NANOAVANSENS Program from Comunidad de Madrid (S2013/MT-3029) is gratefully acknowledged.

\section{Appendix A. Supplementary material}

Supplementary data associated with this article can be found in the online version at doi:10.1016/j.talanta.2015.09.061.

\section{References}

[1] P.R. Galvinas, W. Moreira da Silva, V.M. Rezende, R.A. Moreno, J. Chromatogr. B 877 (2009) 3601.

[2] S.J. Keam, A.J. Wagstaff, Treat. Endocrinol. 2 (2003) 49.

[3] Cardiovascular disease and steroid hormone contraception, Report of a WHO Scientific Group, 877 [i-vii], 2011. pp. 1-89.

[4] M. Raps, J. Curvers, F.M. Helmerhorst, B.E.P.B. Ballieux, J. Rosing, S. Thomassen, F.R. Rosendaal, H.A.A.M. van Vliet, Thromb. Res. 133 (2014) 640-644.

[5] A. Baumann, A. Fuhrmeister, M. Brudny-K, I. Cippel, C. Draeger, T. Bunte, W. Kuhnz, Contraception 54 (1996) 234

[6] C. Schneider, H.F. Schöler, R.J. Schneider, Steroids 69 (2004) 245

[7] K. Fotherby, J.O. Akpoviroro, L. Siekmann, H. Breuer, J. Steroid Biochem. 14 (1981) 499.

[8] R.L. Tacey, W.J. Harman, L.L. Kelly, J. Pharm. Biomed. Anal. 12 (1994) 1303.

[9] I. Coille, S. Reder, S. Bucher, G. Gauglitz, Biomol. Eng. 18 (2002) 273.

[10] C. Schneider, H.F. Schöler, R.J. Schneider, Anal. Chim. Acta 551 (2005) 92.

[11] N.A. Martínez, R.J. Schneider, G.A. Messina, J. Raba, Biosens. Bioelectron. 25 (2010) 1376.

[12] H. Kanso, L. Barthelmebs, N. Inguimbert, T. Noguer, Anal. Chem. 85 (2013) 2397.

[13] A. Walcarius, A. Kuhn, Trac-Trends Anal. Chem. 27 (2008) 593.

[14] T.H. Thi Vu, T.T. Thi Tran, H.N. Thi Le, L.T. Tran, P.H.T. Nguyen, H.T. Nguyen, N Q. Bui, Electrochim. Acta 161 (2015) 335.

[15] S.K. Maji, S. Sreejith, A.K. Mandal, X. Ma, Y. Zhao, ACS Appl. Mater. Interfaces 6 (2014) 13648

[16] G. Wang, X. He, L. Chen, Y. Zhu, X. Zhang, Coll. Surf. B: Biointerfaces 116 (2014) 714

[17] F.H. Cincotto, T.C. Canevari, A.M. Campos, R. Landers, S.A.S. Machado, Analyst 139 (2014) 4634

[18] I. Pastoriza-Santos, L.M. Liz-Marzán, Langmuir 15 (1999) 948.

[19] I. Ojeda, J. López-Montero, M. Moreno-Guzman, B.C. Janegitz, A. GonzálezCortés, P. Yáñez-Sedeño, J.M. Pingarrón, Anal. Chim. Acta 743 (2012) 117.

[20] P. Tijssen, Practice and theory of enzyme immunoassays, in: R.H. Burdon, P. H. van Knippenberg (Eds.), Laboratory Techniques in Biochemistry and Molecular Biology, vol. 15, Elsevier, Amsterdam, 1985, p. 19.

[21] H. Lu, M.P. Kreuzer, K. Takkinen, G.G. Guilbault, Biosens. Bioelectron 22 (2007) 1756.

[22] C.A. Mandon, L.J. Blum, C.A. Marquette, Chem. Phys. Chem. 10 (2009) 3273. 